\title{
Da biopolítica a necropolítica e a racionalidade neoliberal no contexto do COVID-19
}

\author{
From biopolitics to necropolitics and neoliberal rationality in the context of \\ COVID-19
}

\section{Rogério Luis da Rocha Seixas*}

Resumo: Neste artigo, desenvolveremos algumas considerações gerais, referentes a noção de biopolítica e biopoder de Michel Foucault relacionadas com a teoria da Necropolítica, enquanto política de morte e o exercício do necropoder, proposta pelo pensador camaronês Achille Mbembe e como essa se relaciona ao fenômeno de pandemia da Covid-19. Pretendemos assim problematizar, à luz dos aportes teóricos tanto da reflexão perpetrada por Michel Foucault, a partir do conceito de Biopolítica, quanto da noção de Necropolítica proposta por Mbembe, as questões políticas e éticas presentes no contexto da eclosão desta pandemia, objetivando criticar e analisar nossa atualidade política dominada por uma racionalidade neoliberal hegemônica e intensamente destrutiva, presente na forma da gestão das condições de saúde e da vida da população por parte dos Estados.

Palavras-chave: Biopoder; Biopolítica; Covid-19; Necropoder; Necropolítica; Racionalidade Neoliberal

\begin{abstract}
In this article, we pretend to develop some general considerations by regarding Michel Foucault's notion of biopolitical and biopower related with the necropolitics theory, as a death politics and an necropower exercise, proposed by cameroonian thinker Achille Mbembe, and how it is related with the pandemic disease of Covid-19. Thus, we intend to take issue with, in the light of the theoretics contributions on the reflections perpetrated by Michel Foucault, from the Biopolitics concept, and of the Necropolitics notions proposed by Mbembe, the political and ethical issues presents in the context of the pandemic outbreaks, aiming to criticize and to analyze our political current dominated by a hegemonic and intensely destructive neoliberal rationality, present in the state's management on the populations health and life conditions.
\end{abstract}

Keywords: Biopolitics; Biopower; Covid-19; Necropolitics; Necropower; Neoliberal Rationality

\section{Introdução}

Michel Foucault aponta que na Modernidade, o modo de governar se torna essencialmente biopolítico, objetivando gerir a vida dos corpos de uma população, tanto no seu sentido biológico quanto no capital vital de produção. Assim, a vida do corpo espécie humana no coletivo, torna-se alvo de ação política e econômica. Paralelamente, determinamse saberes que controlam, explicam e justificam o exercício de regulação da biopolítica. Nessa configuração, a medicina social emerge ao lado dos poderes soberanos modernos, decorrentes do surgimento dos Estados nacionais. Citando o pensador: "Foi no biológico, no somático, no corporal que, antes de tudo, investiu a sociedade capitalista. 0 corpo é uma realidade biopolítica. A medicina é uma estratégia biopolítica"1.

Em seu curso Segurança, Território e População, Foucault analisa como a epidemia da varíola, ocorrida entre os séculos XVIII e XIX, foi decisiva para o desenvolvimento de técnicas

${ }^{1}$ FOUCAULT, Microfísica do Poder, p.80.

* Pesquisador do Grupo Afrosin, Universidade Federal Rural do Rio de Janeiro, Seropédica, RJ. E-mail: rogeriosrjb@gmail.com ORCID: https://orcid.org/0000-0003-0932-5787 
médicas para o controle de enfermos, tornando-se posteriormente técnicas políticas de regulação da população. Os alertas médicos contra as epidemias e pandemias, entre outros, serviram para modular estas técnicas que possibilitaram o gerenciamento da população, através dos dispositivos de segurança, relacionando-os com a biopolítica. A vida tornou-se o elemento político que legitimou a intervenção sobre o controle da população, em temas como a morbidade, a saúde pública, a higiene e as epidemias. Por consequência, a forma tradicional de se exercer o poder soberano "não mais se limita a segurança do príncipe e do seu território, mas com a segurança da população e, por consequência dos que a governam"2. Não basta governar um Estado, um território ou uma estrutura política, mas agora deve-se governar pessoas, indivíduos, homens e coletividades.

Foucault tece outra observação, quanto à mudança de paradigma do poder soberano, quando se refere ao governo da população. Citando o autor: "O governo das populações é, creio, algo totalmente diferente do exercício de uma soberania sobre até mesmo o grão mais fino dos comportamentos individuais. Temos aí duas economias de poder que são, parece-me, totalmente diferentes" 3 . Uma característica importante do governo, intervindo em escala populacional, reflete-se no fato de que, o Estado não mais se direciona exclusivamente ao governo das condutas dos corpos singulares, característica constitutiva dos procedimentos disciplinares da anátomo-política, destinada a tornar os indivíduos dóceis e úteis. Edgar Castro ressalta a respeito destes dispositivos de poder:

Que não se trata de identifica-los com determinadas histórias, como se houvesse uma época arcaica, a da soberania; outra moderna, a das disciplinas; e outra contemporânea, a da segurança e da biopolítica. Historicamente, não há uma sucessão desses diferentes dispositivos, mas uma simultaneidade 4 .

Identifica-se com efeito, o modo como as diferentes modalidades de exercício do poder, se imbricam entre si, enquanto dispositivos que não são antagônicos, mas complementares. A anátomo-política e a biopolítica, constituem-se como novas técnicas políticas, necessárias para governar a população. A atuação dos poderes disciplinares voltada para a prática de docilizar e tornar os corpos úteis não é simplesmente abandonada, mas passa a integrar o complexo do poder, que enseja a alternância do poder soberano. A pandemia que estamos experimentando, reforça o fato de que a biopolítica não substituiu o poder disciplina e soberano. A estratégia biopolítica de governar a vida, se alia às medidas como por exemplo, o fechamento de fronteiras e a obrigatoriedade do isolamento social, expondo assim o conteúdo soberano-disciplinar da ação governamental.

Em História da Sexualidade: a Vontade de Saber, Foucault assevera que o tradicional direito soberano de "causar a morte ou deixar viver foi substituído por um poder de causar a vida e devolver à morte" 5 . Inaugura-se a "era do biopoder"6. A partir deste novo paradigma, não somos mais governados enquanto sujeitos políticos, mas em nossa condição de seres vivos, que coletivamente formamos uma população. 0 biopoder atua sobre o bios ou a vida, tanto na esfera individual quanto coletiva. Assinalasse que a vida da população passa a ser governada de forma positiva, pois ao potencializá-la, fortalece-se sua capacidade produtiva e consequentemente, potencializam-se os Estados.

No curso intitulado É Preciso Defender a Sociedade, entender a ameaça da letalidade das epidemias ou pandemias, como algo constante para a vida da população e traçar estratégias para combatê-las, se configura enquanto nova forma de governar a vida pelo poder estatal. Citando Foucault: "A tendência que conduz ao que se poderia chamar de

\footnotetext{
${ }^{2}$ FOUCAULT, Segurança, Território e População, p. 85.

3 Ibidem, p. 87.

${ }^{4}$ CASTRO, Introdução a Michel Foucault, pp.109-110.

${ }^{5}$ FOUCAULT, História da Sexualidade I, a Vontade de Saber, p. 130.

${ }^{6}$ Ibidem, p.132.
} 
estatização do biológico"7. Dessa maneira, aumenta-se a qualificação da vida, controlando-se seus acidentes e limitando-se suas deficiências. Segundo o autor:

Doenças mais ou menos difíceis de extirpar, e que não são encaradas como as epidemias, título de causa de morte mais frequente, mas como fatores permanentes - e é assim que as tratam - de subtração das forças, diminuição do tempo de trabalho, baixa de energias, custos econômicos, tanto por causa da produção não realizada quanto dos tratamentos que podem custar. Em suma, a doença como fenômeno da população; não mais como a morte que se abate brutalmente sobre a vida - é a epidemia - mas como a morte permanente, que se introduz sorrateiramente na vida, a corrói perpetuamente, a diminui e a enfraquece ${ }^{8}$.

Todavia, se o essencial não é mais provocar a morte por parte do Estado, mas sim potencializar a vida, notadamente não se aniquila totalmente, a capacidade de se permitir ou criar condições para que vidas sejam exterminadas. Deve-se acentuar que a alteração de paradigma no modo como passa-se a governar o corpo espécie, ou seja, enquanto uma massa global, mesmo com seus resultados positivos, não deixa de apresentar uma extensão negativa na intervenção dos mecanismos de poder estatal.

Por sinal, também em É Preciso Defender a Sociedade, o pensador francês, faz referência ao caráter paradoxal da biopolítica que se insere no fazer viver e deixar morrer, reconhecendose o potencial de morte do biopoder. Contudo, como um poder que visa promover a vida, pode deixar morrer ou mesmo levar à morte? A resposta encontra-se na prática do Racismo de Estado, caracterizando-se como tecnologia de poder que estabelece formas de eliminação dos indesejáveis, dos inúteis, dos descartáveis, objetivando promover a saúde e o bom funcionamento do corpo social. Eliminação realizada pela exclusão de determinados grupos ou indivíduos de seus direitos, por exemplo, à assistência social e aos serviços de saúde, por serem considerados não gestáveis. 0 racismo se configura enquanto a condição para a prática do direito de morte, numa configuração neoliberal e biopolítica do poder. Justificam-se o extermínio e os massacres, seguindo-se a lógica do biopoder, predominante na racionalidade política atual. Neste aspecto, o biopoder exerce o direito de morte e o abandono da vida, em nome da vitalidade do conjunto governado. Em tal circunstância, pode-se descrever a função do racismo de Estado: justificar o exercício de matar em nome da vida, segundo a morte do inferior, do anormal, beneficiando a vida da raça, a tornando mais sadia e pura. Para Foucault: "O imperativo da morte, só é aceitável no sistema de biopoder se tender não para a vitória sobre adversários políticos, mas para eliminação do perigo biológico e para reforço, diretamente ligado a esta eliminação, da espécie ou raça"9. A saúde da população se desloca de acordo com o que se passa a considerar normal ou anormal, catalogando-se doenças como endemias ou pandemias, segundo o que Foucault chama de economia política da medicina, cabendo ao Estado, ao exercer a normalização biopolítica, gestar essa economia política. Outro ponto essencial a ser ressaltado: uma ligação direta entre biopoder e capitalismo. Segundo o pensador:

O biopoder, sem a menor dúvida, foi elemento indispensável ao desenvolvimento do capitalismo, que só pode ser garantido à custa da inserção controlada dos corpos no aparelho de produção e por meio de um ajustamento dos fenômenos de população aos processos econômicos ${ }^{10}$.

\footnotetext{
7 FOUCAULT, É Preciso Defender a Sociedade, p.271.

8 Ibidem, p.260.

${ }^{9}$ Ibidem, pp. 272-273.

10 Ibidem, p. 270.
} 
Trata-se de compreender como o aumento e o confisco das riquezas, supõe o desenvolvimento de poderes que capturam as forças vitais para participarem do processo de criação de riquezas.

Em Nascimento da Biopolítica, Foucault ressalta que a biopolítica se inscreve na história do liberalismo político. Citando o pensador: "Parece-me que só depois de sabermos o que era esse regime governamental chamado liberalismo é que poderemos compreender o que é biopolítica"11. Liberalismo como racionalidade de governar e não um princípio econômico. Neste mesmo curso, Foucault aponta que em nossa atualidade, marcada pelo neoliberalismo, a economia transformou-se em uma técnica de análise, voltada para a programação estratégica das atividades e dos comportamentos dos indivíduos, objetivando tratar de questões como: qual o modo mais eficaz de se produzir e acumular o capital humano? Como manipular e utilizar sua composição? Tais questões envolvem a "racionalidade de governar neoliberal, destacando-se o papel do mercado, atuando de modo semelhante a um tribunal permanente, que regula as metas da economia política, a partir do governo sobre o capital humano"12.

Foucault observa em História da Sexualidade: a Vontade de Saber, que a prática de governar do poder soberano é agora, recoberta pela "capacidade de administração dos corpos e pela gestão calculista da vida"13. Um ponto marcante da biopolítica fica aqui evidente: a assunção da sociedade de regulação, quando se estabelecem dispositivos de poder, que investem no conjunto dos indivíduos, objetivando gerenciar os efeitos oriundos da vida em sociedade. 0 principal objetivo do Estado moderno e das suas instituições, passa a ser o de utilizar a vida humana em seu favor, extraindo dela, tudo aquilo de que necessitava para que seu poder se mantenha e se intensifique. A eclosão de uma pandemia, torna-se um momento efusivo à biopolítica: em nome da prevenção e proteção coletiva, se governam os corpos e limites entre fronteiras reais e imaginárias com relação a saúde. Não se pode deixar de levar em conta que a biopolítica se constitui sempre em uma política de vulnerabilidade diferencial. Ao estabelecer uma hierarquia no valor das vidas, produz-se e amplia-se a vulnerabilidade do modo de governar os corpos, individualmente e principalmente em conjunto.

Na pandemia da COVID-19, esta noção de Foucault, expressa-se de modo bastante evidente, pois essa distinção diante da vida e da morte, envolve um aparato de estratégias e técnicas de gestão sobre a vida, agora nas áreas de saúde e higiene pública, implicando em decisões de quais vidas devem ser maximizadas e as que são passíveis de descartabilidade, por não serem consideradas passíveis de valor, enquanto capital humano a ser gerido. Neste aspecto, o racismo se apresenta como condição para que os Estados modernos legitimem suas intervenções biopolíticas, caracterizadas como exercício do poder de matar. Desta forma, as mortes causadas pelo vírus se enquadram diretamente naquilo que se configurará como a necropolítica: "o fato de expor à morte, de multiplicar para alguns riscos de morte ou, pura e simplesmente, a morte política, a expulsão, a rejeição, etc"14.

\section{Necropolítica, Racismo e a COVID-19}

Em seu ensaio intitulado de Necropolítica, Achille Mbembe assume que "a expressão máxima de soberania reside, em grande medida, no poder e na capacidade de ditar quem deve viver e quem deve morrer"15. Não se trata apenas do poder de morte, que por si só não consiste em soberania, pois essa, em sua fase extrema, é na verdade aquela que faz viver ou

\footnotetext{
${ }^{11}$ FOUCAULT, Nascimento da Biopolítica, p. 47.

12 Ibidem, p.211.

13 FOUCAULT, História da Sexualidade: a Vontade de Saber, p.131.

${ }^{14}$ FOUCAULT, É Preciso Defender a Sociedade, p.216.

15 MBEMBE, Necropolítica. Biopoder, estado de exceção, política da morte, p. 11.
} 
deixa morrer, ou em outros termos, possui o o domínio da vida enquanto vida que completa a dominação. Ao atribuir à soberania o poder de decisão sobre a morte, ou seja, de matar ou permitir viver, Mbembe apresenta a política como a morte que vive uma vida, sendo ainda a necropolítica, a subjugação da vida ao poder da morte, que é o necropoder. Esses dois termos, são importantes para dar conta dos modos pelos quais "armas são empregadas no interesse da destruição de pessoas e na criação de mundos de morte, novas e únicas formas de existência social nas quais populações estão sujeitas a condições de vida que conferem a elas o status de mortos vivos"16. A relação entre o Estado de exceção e a soberania, resulta em uma autoridade de matar não somente controlada pelo Estado, mas sim que passa a ser distribuída por toda a sociedade. 0 sentido de soberania, ganha sua expressão máxima no poder e na capacidade do soberano em decidir quem deve morrer ou viver. 0 autor formula outra importante indagação referente à política contemporânea: como a vida, a morte e o corpo humano estão inseridos na ordem do poder? Mbembe defende que "a noção de biopoder é insuficiente para dar conta das formas contemporâneas de submissão da vida ao poder da morte"17, principalmente que nos auxilie a identificar a possibilidade de matar do poder soberano.

A soberania é descrita como busca constante de um exercício de poder que supera qualquer limite racional e científico. Se para Foucault, a biopolítica ocorre dentro daqueles territórios no qual o poder é exercido por meio de contratos sociais, isto é, num contexto majoritariamente europeu. A necropolítica abrange outros territórios, como as colônias africanas. Mbembe acrescenta que a raça, assim como o racismo, possui um lugar de destaque na racionalidade do exercício do biopoder, pois afinal, "mais do que o pensamento de classe, a raça foi a sombra sempre presente no pensamento e na prática das políticas do Ocidente, especialmente quando se trata de imaginar a desumanidade de povos estrangeiros ou a dominação a ser exercida sobre eles"18. 0 autor africano destaca que em termos foucaultianos "o racismo é acima de tudo uma tecnologia destinada a permitir o exercício do biopoder. Este velho direito soberano de matar"19. Sua função seria regular a distribuição da morte e possibilitar as funções biopolíticas de matar por parte do Estado. Como tecnologia de governo, os seus mecanismos possibilitam ao Estado, o controle biológico da população, a partir de instituições como o sistema de saúde pública na qual, desde o nascimento, as campanhas de vacinação, internação e isolamento, obituário, tudo é regulado pelas normas estatais. Há um exercício de fazer matar sob uma perspectiva que decide justamente em que momento a vida de uma determinada população ou subgrupo ou mesmo indivíduo, deixa de ser economicamente relevante e, consequentemente, pode ser eliminada. Exerce-se o trabalho de morte da política sobre os indivíduos que começam a sobrar, consoante à estrutura neoliberal atual e que não são mais requisitados a despenderem sua força de trabalho no interior de um processo produtivo amplo.

Em nossa contemporaneidade, Giorgio Agamben destaca que qualquer indivíduo corporificado enquanto um homo sacer encontra-se diretamente imbricado nas práticas biopolíticas, principalmente porque o Estado contemporâneo atua na seletividade das vidas"20. Agamben acrescenta que "colocando a vida biológica no centro de seus cálculos, o Estado Moderno não faz mais, portanto, do que reconduzir à luz o vínculo secreto que une o poder à vida nua"21. Investigando qual seria o ponto de intersecção entre o modelo jurídicoinstitucional e o biopolítico, este autor identifica o poder soberano como o conector dessa ligação. Entretanto, há uma racionalidade de governo que cria e permite uma gestão da vida,

\footnotetext{
16 Ibidem, p. 71.

17 Ibidem, p.71.

18 Ibidem, p. 18.

19 Ibidem, pp.18-19.

${ }^{20}$ AGAMBEN, Homo Sacer. O poder soberano e a vida nua I, p. 127.

21 Ibidem, p.14.
} 
mas de um modo peculiar: na relação entre política e vida para que esta possa ser incluída, primeiro ocorre o processo de sua exclusão. Ou seja, "para entrar no campo da política, a zoé a vida nua - primeiramente foi excluída da pólis; e somente séculos mais tarde, com o advento do biopoder, ela retorna à cena, sendo então incluída"22. Verifica-se nesta descrição, a condição de vida nua, uma vida matável, desprovida de qualquer valor para a produção e o consumo, "assinalando o ponto em que a biopolítica se converte necessariamente em tanatopolítica"23. Essa política da morte ao se coadunar com o Estado de exceção, distribui de forma excludente e desigual recursos políticos, econômicos e de saúde, exercendo um exercício de veto por parte do soberano, sobre as condições de vida dos que são classificados como descartáveis e, consequentemente, estabelecendo-se um poder de decisão de exposição à morte dos grupos considerados como impuros ou marginalizados. Esta exposição à morte, marca a invisibilidade que se localiza no cerne do racismo, negando a humanidade do outro e se desenvolvendo como modelo legitimador de exclusão e descarte. Mais do que isso, o racismo representa a escolha de quem deve ser eliminado ou sobreviver, numa morte que pode ser física, política ou simbólica. O exemplo apresentado é o do Negro, enquanto construção social, representando uma noção que designa a imagem de uma existência subalterna ou um outro tipo de humanidade nociva e indesejável.

Partindo deste prisma, pode-se questionar o motivo pelo qual muito pouco se divulga, a situação da COVID-19 na África? Pode tal fato, se relacionar com a invisibilidade das populações que habitam este território, ainda serem consideradas hierarquicamente inferiores? Podem ser classificadas como vidas passíveis de descarte? Qual será de fato o potencial de letalidade que a pandemia provocará em regiões menos preparadas para enfrentá-la? Inseridos em tais questões, pode-se perceber o desprezo e aniquilamento do Outro, próprio do racismo que move a prática do necropoder. Em África, são escassos os equipamentos e materiais técnicos, unidades de tratamento intensivo, médicos, enfermeiros e possui uma rede de proteção social muito vulnerável. Podemos perceber a lógica que atua neste contexto do Coronavírus e da necropolítica que guarda resquícios da colonização: há a classificação entre os que são considerados como pessoas e os denominados enquanto nãopessoas. Têm-se então a Europa branca, permanecendo o centro do poder político e econômico. É a região do colonizador habitada por pessoas. Quanto ao continente africano, periférico na geopolítica mundial, continua a ser percebido enquanto uma colônia, onde habitam as não-pessoas.

0 grau de letalidade produzido pela COVID-19 e neste inserindo-se uma forma de genocídio, não pode ser interpretado como se o vírus tivesse uma essência malvada em si. Deve-se analisar de modo crítico que pandemias deste tipo, são sobretudo fomentadas por políticas que trazem consigo pulsões de morte, ou seja, o exercício pleno da necropolítica. Este projeto genocida se concretiza na condição do "poder soberano de ditar quem pode viver e quem deve morrer (...) quem é descartável e quem não é"24. Existe uma estratégia de deixar morrer, que atinge principalmente, de acordo com Agamben os "indignos da vida" 25 e, portanto, na nossa interpretação, o genocídio em marcha e a biopolítica, se fusionam na produção intensa de mortes, na tentativa de se aniquilar o Outro, sendo este percebido sob a ótica do inimigo e também, sob a lógica da guerra, necessitando portanto, ser exterminado. Desse modo, torna-se imprescindível ressaltar que inserido na política de morte, identifica-se uma característica própria do racismo necropolítico, reconhecendo-se o Outro como ameaça mortal ou um perigo absoluto, se fazendo necessária sua eliminação, para reforçar o potencial de vida e manter a segurança de uma população ou grupo considerado hierarquicamente superior. Trabalhando a partir desta premissa, Mbembe visa identificar a existência de um

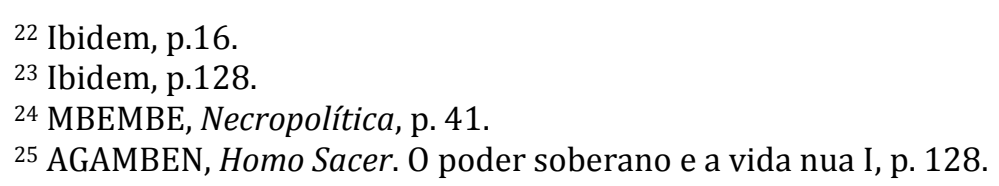


vínculo entre a política de extermínio e a guerra, onde a "racionalidade da vida passe pela morte do outro; ou que a soberania consiste na vontade e capacidade de matar a fim de viver"26. Pode ser bem ilustrativa, a fala do atual soberano dos EUA:

Precisamos das máscaras. Não queremos outros conseguindo máscaras. É por isso que estamos acionando várias vezes o ato de produção de defesa. Você pode chamar de retaliação porque é isso mesmo. Se as empresas não derem o que precisamos para nosso povo, nós seremos mais duros ${ }^{27}$.

Atente-se para a contundência em se proibir que as empresas não devam vender material médico necessário ao combate contra a pandemia, para a América Latina, reconhecida aqui como região habitada por sub-humanos e matáveis. Evidencia-se uma postura própria à soberania, arrogando-se da "capacidade em definir quem importa e quem não importa viver"28.

\section{Políticas de Morte, Racionalidade Neoliberal e a Covid-19}

Em Nascimento da biopolítica, Michel Foucault destaca que para se compreender a biopolítica, deve-se desvelar a lógica da racionalidade política neoliberal que diferentemente do liberalismo clássico, visa "reconstituir não o homem do intercambio, não é o homem consumidor, mas o homem da empresa e da produção" 29 . Passa-se a aplicar o princípio da racionalidade empresarial das condutas e ações dos indivíduos nas teorias do capital humano. O principal objetivo do neoliberalismo passa a ser que o modo de governar a sociedade tenha agora a forma de uma empresa. Observa o pensador que "tratase de constituir uma sociedade indexada não mais à mercadoria nem à uniformidade da mercadoria, mas à multiplicidade e à diferenciação das empresas" ${ }^{30}$. Esse sistema empresa/sociedade passa a operar com um aparato de cálculo. A ideia de que alguém vale mais do que os outros. Quem não tem valor pode ser descartado. A questão é o que fazer com aqueles que decidimos não ter valor. Essa problematização, é claro, sempre afeta as mesmas raças, as mesmas classes sociais e os mesmos gêneros. É por esse motivo que Mbembe observa a existência de uma verdadeira economia da violência ${ }^{31}$, relacionada com a formação de um mercado/empresa no corpo social e, simultaneamente, a constituição de uma rede de serviços voltados para a produção da morte na sociedade.

Essa percepção econômica e eventualmente política, sob o viés de Mbembe, inicia-se na fase mercantilista do capitalismo, quando o negro é transformado em mercadoria e que perdura no neoliberalismo, ampliando-se para outros grupos que podem ser elimináveis e matáveis, podendo ser colocados como hierarquicamente inferiores quanto a necessidade de assistência social e sanitária, sendo expostos às situações de morte como no caso de pandemias semelhantes a do Coronavírus. A escalada de mercantilização de diferentes dimensões da vida social, por exemplo, é indissociável desta condição destrutiva da racionalidade neoliberal dos Estados atuais. Em seu ensaio Crítica da Razão Negra, o autor ressalta que os corpos são classificados como supérfluos e descartáveis quando as suas capacidades de trabalho diminuem ou cessam, ou ainda, ao não se constituírem mais como

\footnotetext{
26 MBEMBE, Necropolítica, p.20.

27 Discurso proferido por Donald Trump, em tom de ameaça contra empresas que vendessem mascaras e equipamentos essenciais no combate a pandemia, para a América Latina e Canadá, defendendo a exclusividade e manutenção da vida da população norte-americana, em detrimento da morte de outras consideradas "descartáveis" e "inferiores".

28MBEMBE, Necropolítica, p.41.

${ }^{29}$ FOUCAULT, Nascimento da biopolítica, p. 175.

30 Ibidem, p. 193.

31 BARRIOS, Necropolítica, una revisión crítica, p. 137.
} 
necessários ao modo de reprodução próprio ao neoliberalismo. 0 pensador afirma que tal situação representa a inexistência de trabalhadores propriamente ditos. Significa dizer que no quadro neoliberal, "só existem nômades do trabalho, sendo estes relegados a uma humanidade supérflua, entregues ao abandono e sem qualquer utilidade para o funcionamento do capital, tornando-se dispensáveis e até mesmo, convertendo-se em vidas matáveis, exatamente por se tornarem inúteis"32.

A necropolítica define estratégias que resultam na morte de corpos considerados inúteis ou inadaptáveis aos padrões da gestão neoliberal, que se estrutura num sistema baseado na distribuição desigual da oportunidade de viver e de morrer. Tudo aquilo que representar algum obstáculo a mercantilização plena da vida e sua administração deverá ser eliminado. Observe-se que com a mercantilização da vida, paradoxalmente, esta deve ser eliminada. Principalmente a vida daqueles cuja condição existencial encontra-se precarizada ao ponto de serem descartáveis.

0 pensador camaronês adverte que "a Modernidade sempre esteve nas origens de diferentes e diversificados conceitos de soberania e, por conseguinte, embasando-se na prática da biopolítica"33. Por este motivo, sua reflexão não se limita aos eventos do holocausto judeu e dos governos denominados como totalitários. A meta primordial é tratar das "soberanias cujo projeto central é a instrumentalização generalizada da existência humana e destruição de corpos humanos e populações" ${ }^{34}$. Mbembe vai além, afirmando que tais formas de soberania "constituem o nomos do espaço político em que ainda vivemos"35. Ainda, conforme este pensador, para analisar a soberania na política atual, devem-se utilizar "outras categorias fundadoras menos abstratas e mais palpáveis, tais como a vida e a morte" 36 .

Tal perspectiva nos direciona para outro ponto importante, que se refere ao estudo de Mbembe, acerca dos regimes pós-coloniais africanos, apontando para uma relação direta entre soberania e propriedade, quando a partir da figura do escravo, afirma-se a desigualdade do poder soberano sobre a vida. Conforme este pensador: "Esse poder sobre a vida do outro, assume a forma de comércio: a humanidade de uma pessoa é dissolvida até o ponto em que se torna possível dizer que a vida do escravo é propriedade do seu senhor"37. Coisifica-se a vida de tal maneira, que a manutenção das condições de fazer viver ou a destruição destas para causar a morte, obedecem simplesmente às decisões e interesses de poder e economia. $\mathrm{Na}$ prática, pode-se destacar como exemplo dessa estratégia, o desmonte da coisa pública em função da coisa privada para validar a gestão dos meios que garantem aquilo que nos termos observados por Foucault em É Preciso Defender a Sociedade defesa da sociedade, fazem com que "o corte entre o que deve viver e morrer"38 estejam ligadas meramente aos interesses econômicos e não ao bem-estar geral. Saliente-se que a racionalidade neoliberal de governar/administrar a vida da população, impõe a necropolítica pela violência, mas que nem sempre essa é explícita, quando por exemplo, gerenciam-se e determinam-se cortes na saúde pública, criam-se mecanismos para a mercantilização e a privatização da saúde, que deveria ser de acesso à grande maioria, aos mais vulneráveis e necessitados. Temos uma violência discreta. Não matam a tiros os doentes das listas de espera. Mas, quantos morrem nessas listas intermináveis, organizadas pelos gestores da saúde pública, para que a saúde privada possa sugá-la? Tal situação, reflete-se no sofrimento e na morte lenta dos doentes, e quando irrompe uma pandemia como a da COVID-19, devido ao desmonte da estrutura pública de saúde, os mais vulneráveis passam a ser expostos à morte.

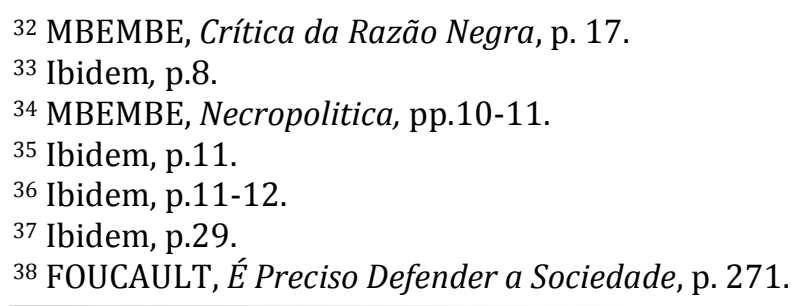


Sob este aspecto, não encontrando valor de produção nos corpos idosos, a lógica neoliberal associada a necropolítica, nos leva inclusive a minimizar a consideração pela vida dos idosos, na medida em que pouco mais poderão contribuir para a dinâmica sistêmica da empresa/sociedade, sendo aceitável serem sacrificados, enquanto mais vulneráveis à COVID19. Neste contexto, a biopolítica se torna uma necropolítica, quando o poder soberano dos Estados modernos, planificado por uma política neoliberal, determina quem irá morrer ou viver, atingindo essencialmente à precariedade das condições e do espaço de vida não apenas dos mais vulneráveis, mas assim como também ameaçando os mais pobres, com praticamente pouco ou nenhum acesso ao sistema de saúde, encontram-se expostos as estratégias do necropoder, presentes na disseminação do vírus. Enfatize-se que as políticas de morte, em termos da racionalidade neoliberal, respondem à uma forma de controle social total, buscando contornar as contradições e fissuras sociais inerentes à crise de acumulação do capital.

Destaque-se, que além da necropolítica encontrar-se associada ao neoliberalismo, sua prática também indica o surgimento de faces inéditas de estruturas autoritárias, representando uma ameaça à estabilidade de nossas democracias. Como atesta o autor: "O principal choque da primeira metade do século XXI não será entre religiões ou civilizações. Será entre a democracia liberal e o capitalismo neoliberal, entre o governo das finanças e o governo do povo, entre o humanismo e o niilismo" 39 . Perante tal realidade, Mbembe declara o fim do que identifica como a era do humanismo, devido exatamente à incompatibilidade da estrutura neoliberal com a democracia liberal, pois não se reconhecem mais limites na aplicação das políticas de morte. Conforme o autor argumenta no texto A Era do Humanismo está terminando:

Isso explica a crescente posição anti-humanista que agora anda de mãos dadas com um desprezo geral pela democracia. Chamar esta fase da nossa história de fascista poderia ser enganoso, a menos que por fascismo estejamos nos referindo à normalização de um estado social da guerra. Tal estado seria em si mesmo um paradoxo, pois, em todo caso, a guerra leva à dissolução do social. No entanto, sob as condições do capitalismo neoliberal, a política se converterá em uma guerra mal sublimada. Esta será uma guerra de classe que nega sua própria natureza: uma guerra contra os pobres, uma guerra racial contra as minorias, uma guerra de gênero contra as mulheres, uma guerra religiosa contra os muçulmanos, uma guerra contra os deficientes ${ }^{40}$.

O capitalismo neoliberal deixou em sua esteira, uma multidão de sujeitos destruídos, muitos dos quais estão profundamente convencidos de que seu futuro imediato será uma exposição contínua à violência e à ameaça existencial. Eles anseiam genuinamente um retorno, a certo sentimento de certeza - o sagrado, a hierarquia, a religião e a tradição.

Apesar da pandemia não ser eletiva em seu contágio, sua manifestação demonstra-se extremamente desigual com relação ao seu tratamento, pois tanto a classe média quanto a alta, encontram uma rede ampla de tratamento intensivo em hospitais privados, que teoricamente apresentam mais recursos. Em contrapartida, as classes baixas, sequer possuem acesso aos leitos, já superlotados dos hospitais públicos. A morte nesse formato acentua a condição da putrefação que retroalimenta o lucro. Sob tal configuração, o sacrifício dos descartáveis, apresenta-se como condição necessária, havendo a supressão de qualquer mediação jurídico-política-ética. Inclusive, o tão famoso imperativo categórico kantiano em que o homem se apresenta na condição de um fim em si mesmo e não como um meio, perde totalmente sua validade, pois demarca que cada ser humano possui sua dignidade, não podendo ser medido conforme um valor ou preço. Mbembe ressalta que "a noção humanística

${ }^{39}$ MBEMBE, A Era do Humanismo está terminando, p.4.

40 Ibidem, pp.5-6. 
e iluminista do sujeito racional capaz de deliberação e escolha, será substituída pela do consumidor conscientemente deliberante e eleitor"41. Convenientemente, a exposição à COVID-19, se transforma em mecanismo de eliminação e descarte ideal, pois ao atingir os indivíduos pertencentes aos denominados grupos de risco, como os idosos ou incapacitados para o trabalho, estes tornam-se plenamente sacrificáveis. Sua eliminação ou sacrifício, passa a ser justificada em consonância à lógica neoliberal, que visa manter a saúde econômica do corpo social administrável.

\section{Conclusão}

Assim sendo, nos moldes da biopolítica, a necropolítica exerce tanto as políticas de administração da vida como também políticas de administração da morte, tratando-se de ações que definem, ao mesmo tempo, o tipo de vida que são administrativamente rentáveis e por consequência, que devem ser preservadas e o tipo de vida que pode e deve ser sacrificável, deixando que seja exposta a morte. São corpos não rentáveis para a racionalidade e prática política neoliberal, que não produzindo e não consumindo, são deixados para morrer. E apesar dos tons democráticos sobre o contágio e letalidade da pandemia do Coronavírus, o poder necropolitico de relativizar a importância de determinadas vidas em detrimento de outras, encontra-se repleto de arbitrariedades, que sobrepõe às preocupações econômicas sobre o valor da vida humana, retratando o poder de morte que emana da racionalidade neoliberal, referentemente à distribuição desigual das oportunidades de viver. Além disso, percebe-se o surgimento e recrudescimento acentuado de autoritarismos políticos que passam a atuar como princípios cada vez mais intensos na articulação entre neoliberalismo e necropolítica, tornando-se uma ameaça para as nossas democracias. Em seu núcleo duro, a democracia liberal torna-se cada vez mais incompatível com a racionalidade do capitalismo neoliberal. Não por acaso, Mbembe se recusa a tratar das noções tradicionais de soberania que normatizam nossas democracias, embasadas em discursos de autonomia e autolimitação, para discutir as formas modernas de poder soberano. 0 autor camaronês faz um alerta:

Como os mercados estão se transformam cada vez mais em estruturas e tecnologias algorítmicas, o único conhecimento útil será algorítmico. Em vez de pessoas com corpo, história e carne, inferências estatísticas serão tudo o que conta. As estatísticas e outros dados importantes serão derivados principalmente da computação. Como resultado da confusão de conhecimento, tecnologia e mercados, o desprezo se estenderá a qualquer pessoa que não tiver nada para vender ${ }^{4}$.

Prática que estamos vivenciando neste contexto de pandemia, quando se deixa de atender pessoas na faixa dos 70 aos 90, para dar possibilidades de fazer viver outros grupos de faixas etárias mais jovens, que segundo o cálculo de gestão próprio a racionalidade neoliberal, são úteis para produção e lucro, enquanto os outros são desprezados e passíveis de descartabilidade.

A pandemia desvela como o neoliberalismo reinante, destruiu e debilitou instituições ligadas a saúde pública e higiene, que são cruciais para enfrentar uma crise como a que estamos passando. Em realidade, o neoliberalismo, com seu racismo, sua necropolítica, sua biopolítica, mais as políticas de austeridade e desigualdade massiva em riqueza e poder, aliada ao desmonte do Estado de bem-estar, configura-se enquanto força letal, que atacando o corpo social, possibilitará o surgimento de pandemias talvez mais letais.

\footnotetext{
41 Ibidem, p.4.

42 Ibidem, p.5.
} 


\section{Referências}

AGAMBEN, Giorgio. Homo Sacer. O poder soberano e a vida nua. Tradução de Henrique Burigo. Belo Horizonte; Editora UFMG, 2002.

BARRIOS, Juan et al. Necropolítica, una revisión crítica. México: Universidad Autónoma de México, 2012.

CASTRO, Edgar. Introdução a Foucault. Tradução de Beatriz de Almeida Magalhães. Belo horizonte: Autêntica Editora, 2014.

FOUCAULT, Michel. Nascimento da Biopolítica. Tradução de Pedro Elói Duarte. Lisboa: Edições 70, 2010.

FOUCAULT, Michel. Segurança, Território, População. Cursos do Collége de France. (19771978). Tradução de Eduardo Brandão. São Paulo: Editora Martins Fontes, 2009.

FOUCAUlT, Michel. É Preciso Defender a Sociedade. Curso do Collége de France (19751976). Tradução de Carlos Correia M. de Oliveira. Lisboa: Editora Livros Brasil, 2006.

FOUCAULT, Michel. História da sexualidade 1. Vontade de Saber. Tradução de Maria Thereza Albuquerque \& J. A. Albuquerque. Rio de janeiro: Edições Graal, 1988.

FOUCAUlT, Michel. Microfísica do Poder. Tradução de Roberto Machado. Rio de Janeiro: Edições Graal, 1979.

MBEMBE, Achille. Necropolítica. Biopoder, soberania, estado de exceção, política da morte. Tradução de Renata Santini. Rio de Janeiro: n-1 edições, 2018.

MBEMBE, Achille. A Era do Humanismo está terminando. Tradução de André Langer. Revista do Instituto Humanitas Unisinos/IHU- On-line- Edição 186 - São Leopoldo/RS, 2017.

MBEMBE, Achille. Crítica da Razão Negra. Tradução de Marta Lança. Lisboa: Editora Antígona, 2014. 